\title{
Anabases
}

ANABASES Traditions et réceptions de l'Antiquité

19 | 2014

Varia

\section{Anne GANGLOFF (éd.), Lieux de mémoire en Orient grec à l'époque impériale}

\section{Cyrielle Landrea}

\section{(2) OpenEdition}

\section{Journals}

Édition électronique

URL : http://journals.openedition.org/anabases/4731

DOI : 10.4000/anabases.4731

ISSN : 2256-9421

\section{Éditeur}

E.R.A.S.M.E.

\section{Édition imprimée}

Date de publication : 1 avril 2014

Pagination : 343-345

ISSN : 1774-4296

\section{Référence électronique}

Cyrielle Landrea, «Anne Gangloff (éd.), Lieux de mémoire en Orient grec à l'époque impériale », Anabases [En ligne], 19 | 2014, mis en ligne le 01 avril 2014, consulté le 22 septembre 2020. URL : http:// journals.openedition.org/anabases/4731; DOI : https://doi.org/10.4000/anabases.4731

Ce document a été généré automatiquement le 22 septembre 2020.

(c) Anabases 


\title{
Anne GANGLOFF (éd.), Lieux de mémoire en Orient grec à l'époque impériale
}

\author{
Cyrielle Landrea
}

\section{RÉFÉRENCE}

Anne GANGLOFf (éd.), Lieux de mémoire en Orient grec à l'époque impériale, Bern, Peter Lang SA, 2013, $395 \mathrm{p}$.

50 euros / ISBN 978-3-0343-1375-9

1 Issu d'un colloque international tenu à Lausanne, en 2011, cet ouvrage s'inscrit dans la vaste réflexion sur la mémoire, en vogue depuis plusieurs décennies. L'historiographie française des questions mémorielles tire largement son origine des travaux des contemporanéistes et l'œuvre dirigée par Pierre Nora sur les Lieux de mémoire est rapidement devenue une référence dans ce domaine (François Jéquier montre d'ailleurs tout le cheminement intellectuel de ce concept au cours des dernières décennies).

2 Anne Gangloff effectue un bilan historiographique commode des études mémorielles, en mettant l'accent sur les travaux les plus récents, consacrés à l'Antiquité. L'optique du colloque embrassait les grandes thématiques récentes, à savoir la politische Kultur (perceptible dans le contrôle de la memoria collective par les dirigeants), l'anthropologie avec les objets et pratiques mémoriels; mais aussi la mémoirecommémoration, la concurrence mémorielle, la construction littéraire et rhétorique, ainsi que l'incontournable concept de "mémoire collective». Afin de donner une cohérence et une ligne directrice aux communications, les lieux matérialisés ont été privilégiés. Par conséquent, les lieux symboliques inclus dans la définition de Pierre Nora ont été écartés.

3 La première partie est dédiée à la géographie imaginaire de la mémoire hellène, à commencer par les voyages d'Apollonios de Tyane, selon Philostrate qui dresse 
l'inventaire des lieux visités (Ewen Bowie). Francesca Mestre s'intéresse à l'identité hellénique dans l'Heroikos de Philostrate, qui met en lumière la construction mémorielle des élites grecques sous le Principat, à travers divers thèmes, tels les cultes héroïques. Il n'existe en fait pas de mémoire-hommage et il s'agit d'une memoria antihistorique.

Le deuxième thème abordé concerne la construction des lieux de mémoire dans le discours rhétorique et l'iconographie. Pilar Gómez traite la place de Marathon dans l'identité grecque au II $\mathrm{s}$. ap. J.-C., véritable symbole de la mémoire collective. C'est une mémoire ectopique, indissociable d'Athènes et de son âge d'or, transmise par l'atticisme littéraire et la paideia. Puis Borysthène dans le discours 36 de Dion Chrysostome est au cœur de l'analyse d'Alain Billault. Cette cité dispose d'une triple sédimentation mémorielle (culturelle, historique et philosophique) et vit dans le souvenir d'une grandeur perdue. Talila Michaeli s'intéresse aux allusions au Nil et au paysage nilotique dans l'art en Israël, qui constituèrent un héritage culturel transmis et adapté aux époques romaine et chrétienne.

Les interactions entre l'identité civique et les lieux de mémoire constituent la troisième thématique. Claude Bérard examine d'abord l'exemple de l'herôon de l'évergète Opramoas à Rhodiapolis, dont les murs, couverts d'inscriptions, font office de conservatoire archivistique. L'exposition de ces archives civiques matérialise une "mémoire éternelle». Un autre ensemble monumental est étudié par Marietta Horster : le sanctuaire de Déméter et de Koré à Eleusis. L'approche diachronique ( $\mathrm{du}^{\mathrm{e}}$ s. av. au $\mathrm{III}^{\mathrm{e}} \mathrm{s}$. ap. J.-C.) met en lumière les différentes strates mémorielles, notamment visibles à travers le dossier épigraphique. Olivier Gengler se consacre à une aire géographique plus large: les sanctuaires $d u$ sud du Péloponnèse. Les élites $y$ investissent certains espaces (en laissent dépérir d'autres), en fonction de l'image du passé dégagée. Messène et Sparte sont des cas particuliers où la mémoire paraît figée.

Une section est dédiée aux topographies sacrées, à commencer par l'incontournable sanctuaire de Delphes. Anne Jacquemin présente un Apollonion méconnu, celui des lieux sans mémoire qui ne sont pas mentionnés par les sources, tel le double monument triangulaire offert par les Messéniens au $\mathrm{V}^{\mathrm{e}} \mathrm{s}$. Un autre exemple précis est traité par Christian Raschle, celui du temple d'Apollon à Daphné et de ses transformations mémorielles. C'est ici surtout la pratique divinatoire qui définit la stratégie mémorielle païenne et le martyrion de Babylas pour les autres. Les conflits opposant les chrétiens aux païens au $\mathrm{IV}^{\mathrm{e}} \mathrm{s}$. sont caractéristiques de la compétition entre plusieurs mémoires collectives. Jean-Sylvain Caillou s'intéresse quant à lui au tombeau de Jésus. Ce lieu de mémoire a clairement une fonction théologique et se construit aussi par rapport à des référents païens.

7 La dernière section est la plus importante avec pas moins de cinq contributions et porte sur la place des empereurs dans les lieux de mémoire. La fondation de Nicopolis par Octavien commémore Actium, affirme son idéologie et le philhellénisme romain, tout en développant cette partie du nord-ouest de la Grèce (Eric Guerber). Dans la même lignée, Christine Hoët-van Cauwenberghe et Maria Kantiréa traitent le mythe d'Actium jusqu'aux Sévères. Nicopolis est porteuse d'une mémoire purement romaine en Grèce, conforme à l'idéologie de la victoire, mais c'est aussi une mémoire déchirée pour certains membres de la domus Augusta, voire à réinvestir dans le cas néronien (Néronikopolis). Les deux contributions suivantes s'intéressent à des lieux de mémoire à ciel ouvert, avec en premier lieu les Portes de Cilicie (Stéphane Lebreton). La modélisation spatiale les fait apparaître sous la forme d'une frontière mentale entre 
l'Asie mineure, un Orient connu, et un autre plus lointain. Ensuite Caroline Blonce traite l'appropriation romaine d'un lieu de mémoire grec, Issos. En réinvestissant la figure d'Alexandre le Grand, Septime Sévère trouve un moyen supplémentaire de légitimer son pouvoir. Enfin Agnès Bérenger étudie la réutilisation des lieux de mémoire orientaux par Caracalla durant son voyage et la construction de la figure du « Nouvel Alexandre ».

8 Les stratégies mémorielles visibles ici sont celles des vainqueurs et le fruit d'une sélection drastique du passé. L'approche diachronique embrasse une chronologie vaste, de l'époque classique à l'Antiquité tardive, permettant de dresser une typologie des lieux de mémoire. En outre la diversité des exemples traités permet de mieux considérer les vecteurs humains, ainsi que les mécanismes de la constitution d'une mémoire matérielle. Anne Bielman dresse le bilan des apports du colloque à la fin de l'ouvrage. Par l'ampleur de la documentation brassée et par l'éclectisme des interventions, nous retiendrons que ce livre est une étape supplémentaire dans notre connaissance des loci memoriae.

\section{AUTEURS}

\section{CYRIELLE LANDREA}

Université Paris I Panthéon-Sorbonne

cyrielle.landrea@orange.fr 